\title{
Endoscopic papillary large balloon dilation for pancreatic duct stone: a first report
}

A 44-year-old woman, who had been a heavy drinker, was admitted to our hospital for treatment of a pancreatic duct stone with chronic pancreatitis. She had a previous history of endoscopic sphincterotomy for bile duct stones.

Her laboratory examination showed no abnormalities. Contrast-enhanced computed tomography and magnetic resonance cholangiopancreatography revealed a large pancreatic duct stone with a diameter of $10 \mathrm{~mm}$ within the main pancreatic duct (MPD) in the pancreatic head, causing proximal dilation of the MPD (ฉ Fig. 1). During endoscopic retrograde cholangiopancreatography, endoscopic papillary large balloon dilation (EPLBD) with a balloon catheter (Giga II EPLBD Balloon catheter; Century Medical, Tokyo, Japan) was performed, and a large pancreatic duct stone was successfully removed without any adverse events ( Fig. 2, $>$ Fig. 3, > Video 1).

Pancreatic duct stones are a common complication of chronic pancreatitis. Although extracorporeal shock wave lithotripsy (ESWL) is the most common method of treating pancreatic duct stones, large stones remain a therapeutic challenge. This is the first reported case in which EPLBD was performed in the pancreatic duct and a large pancreatic duct stone was successfully removed without using ESWL. Although further clinical studies with larger samples and long-term follow-up are needed to validate and assess its safety, EPLBD should be one of the standard methods of treating pancreatic duct stones.

Endoscopy_UCTN_Code_TTT_1AR_2AH

\section{Competing interests}

The authors declare that they have no conflict of interest.
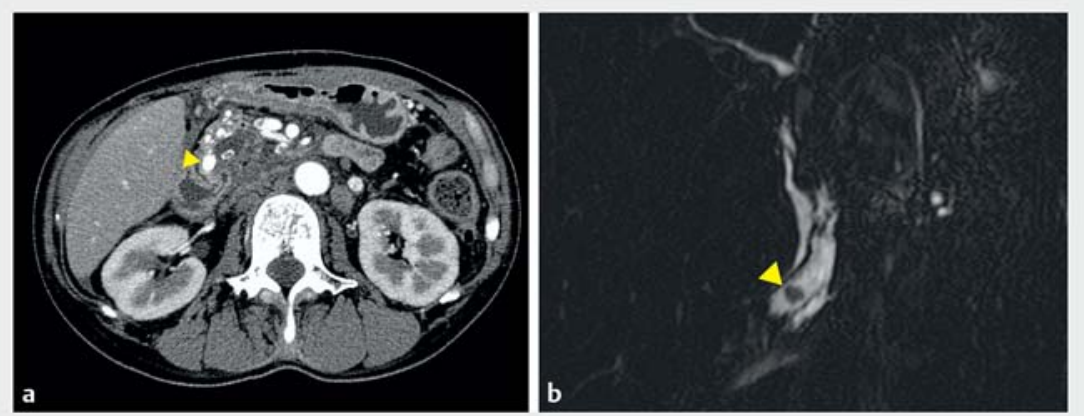

- Fig. 1 Initial imaging studies showed a large pancreatic duct stone (arrowhead) within the main pancreatic duct (MPD) in the pancreatic head, causing proximal dilation of the MPD. a Contrast-enhanced computed tomography. b Magnetic resonance cholangiopancreatography.
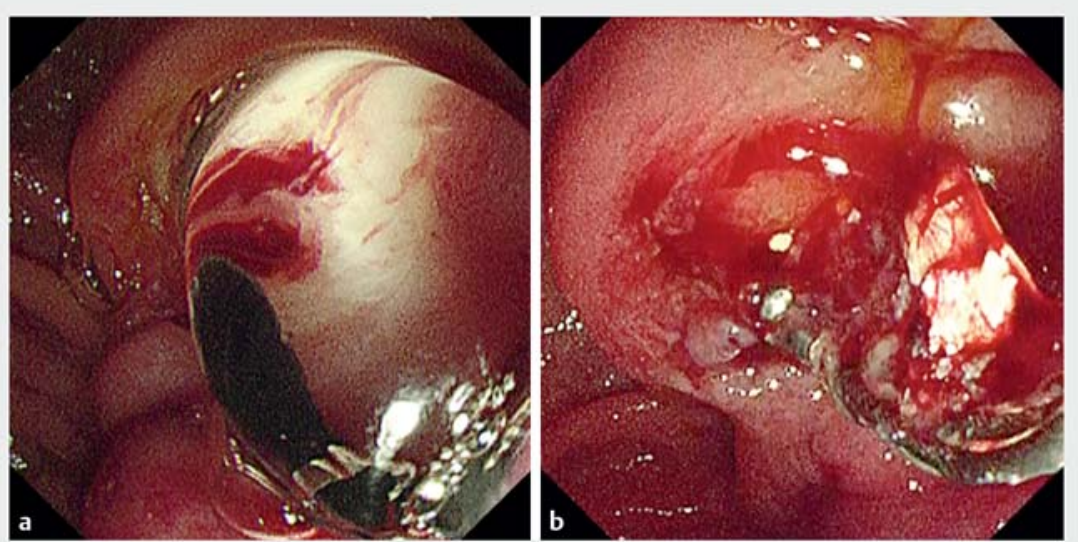

- Fig. 2 Endoscopic views. a The ampullary orifice during endoscopic papillary large balloon dilation of the pancreatic duct. $\mathbf{b}$ The large pancreatic duct stone was successfully removed using a basket catheter.

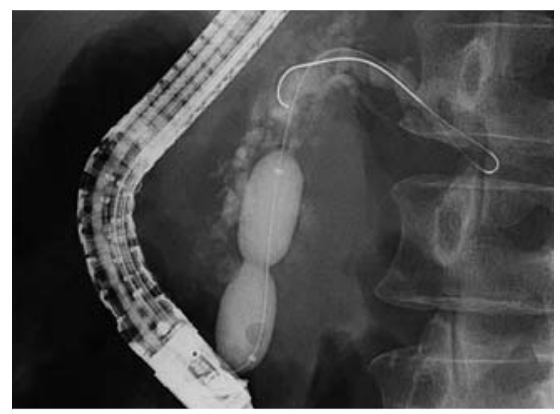

- Fig. 3 Fluoroscopic view during endoscopic papillary large balloon dilation. 


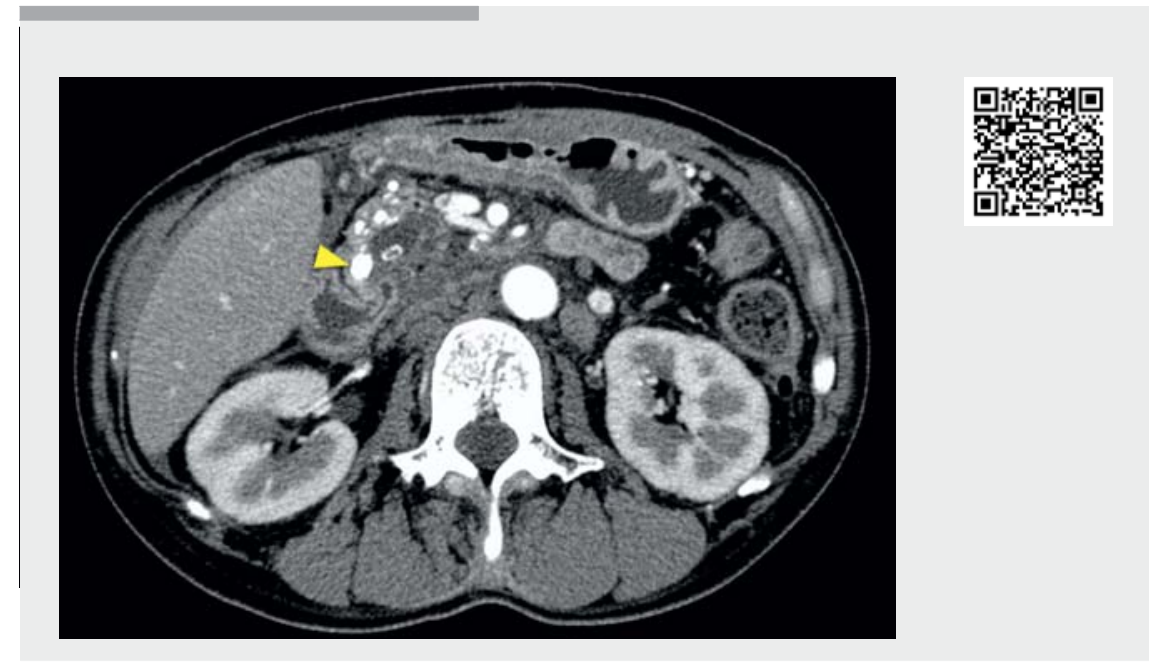

Video 1 During endoscopic retrograde cholangiopancreatography, endoscopic papillary large balloon dilation with a balloon catheter was performed and a large pancreatic duct stone was successfully removed.

The authors

Kosuke Iwano, Akira Kurita, Yoshiharu Mori, Shunjiro Azuma, Shujiro Yazumi Department of Gastroenterology and Hepatology, Kitano Hospital, Tazuke Kofukai Medical Research Institute.

\section{Corresponding author}

Akira Kurita, MD, PhD

Department of Gastroenterology and Hepatology, Kitano Hospital, Tazuke Kofukai Medical Research Institute, 2-4-20,

Ohgimachi, Kita-ku, Osaka 530-8480, Japan Fax: +81-6-63610588

kuritaaki1976@gmail.com

\section{Bibliography}

DOI https://doi.org/10.1055/a-1071-7649

Published online: 20.12.2019

Endoscopy 2020; 52: E213-E214

(c) Georg Thieme Verlag KG

Stuttgart · New York

ISSN 0013-726X

\section{ENDOSCOPY E-VIDEOS \\ https://eref.thieme.de/e-videos}

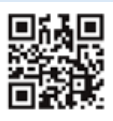

Endoscopy E-Videos is a free access online section, reporting on interesting cases and new techniques in gastroenterological endoscopy. All papers include a high quality video and all contributions are freely accessible online.

This section has its own submission website at https://mc.manuscriptcentral.com/e-videos 